\title{
THE RELATION
}

\section{BETWEEN GAMERS AUDIENCES AND GAMING INDUSTRY WORKFORCE}

IVAN BARROSO

* Instituto Politécnico de Leiria

\section{ABSTRACT}

Relationships between gaming audiences and the industry workforce has been a significant factor for decades, becoming an economic driver for high-profile studios, which has led to an increase in budget size and a tightening of deadlines. The definition of creative media products under capitalism as "research, product planning and design, packaging, publicity and promotion, pricing policy, and sales and distribution" (Ryan, 1991, p.186) resonates perfectly with contemporary marketing strategies The inherent complexity of marketing strategy in this view accounts for heightened risks, which make the creation of original products from scratch a difficult proposition. This in turn can account for a certain aversion to risk, which makes sequels and serialization a preferred option, whereby games become mere products, and audience mere consumers. The aim of this article is to trace the process through which the games industry's core audience became defined, as it relates to how certain game titles became established in the market, and how this affected working conditions for game developers. The scope of this article is big budget game titles, and how these related to the establishment of certain pervasive, potentially harmful audience expectations in the games industry.

Author Keywords: game studies, games industry workforce, audiences 


\section{The Industry Created Bro-gamers}

In the entertainment sector, there is hardly a more entitled demographic of consumers than the one formed in the gaming industry - the Gamer. In truth, it has no mass equivalent in the other creative media industries. Where television broadcasters can call their audience "dear viewers", radio can open their broadcast thanking "every listener out there", and cinema can smile upon the "enthusiastic moviegoer", their mass audience itself (commonly) use these terms as badges of honor. But in videogames that isn't the case. Videogame consumers are proud of their "gamer" status, they act as a collective, and treat videogame titles as something they own, in a particular phenomenon of entitlement and cultural ownership. Some even prefer the term "harcore gamer" to distinguish themselves from others. It's a proud audience, and for a long time, the core of the industry.

As Kubik (2010, p.59) points out, traits of this gamer ideology may include a disproportionate weight of game-playing and game-related activities in a person's daily schedule, to the detriment of other daily activities, which may extend to basic grooming and hygiene. Other authors like Juul (2010, p. 29), identifies these "gamers" with a desire to use high difficulty settings on their games, leading to identification (either by themselves or others) as "hardcore gamer" or "brogamers". The demographic profile within this phenomenon are male teenagers and young adults. "The bro gamer discourse speaks about, but rarely to, a large demographic of 'non-geek' gamers, and embodies a set of cultural values which are better understood within a broader picture of patterns of cultural consumption within Western societies." (Baxter-Webb, 2014, p.8)
Studies in Europe, specifically in Norway and France (Rufat, et.al, 2012), have demonstrated that male audiences from working class background, have a particular interest in action games, such as racing, sports, competitive and shooters, therefore it's both a wider and narrow audience. Unfortunately, it's also not uncommon that negative portraits of this consumer appear on the mass media as part of negative issues related to videogames.

Consequently, during a long period of time the high-profile gaming industry was explicitly focused on this audience, and the products were created mostly by male game developers, aimed at male audiences. Under these circunstances, in order for someone to be considered a worker in the gaming industry, firstly he had to be a gamer (Christiansen, 2013). Gamers as an audience are present from the industry's beginnings, ever since the first players started competing, either in arcades or in domestic smaller spaces, or in official tournaments.

An example of how gamer cultures fed into developer cultures and consequently turn into gamer cultures, is the public persona of developer John Romero. Can be argued that the co-founder of id Software (Wolfenstein 3D, Doom, Quake) have helped to shape gaming audience's eSports behaviour and game expectations. Kushner (2003), mention that Romero was an avid gamer that would show up at Doom videogames tournaments to participate, while loudly trash-talking his opponents ${ }^{1}$, moreover Kushner points out that this behaviour was soon imitated among the younger crowd. Ever since, it's become common for online and competitive gamers to become louder with every play that shames their opponents. Game developing companies took notice, and popular competitive games are also famous for praising a player's performance 2 . Ensslin (2012), recognizes that gaming audiences even

1 It should be mentioned that this sort of negative dialogue wasn't uncommon before, it was just that a developer that was a reference in the industry, also adopted it, and could have contributed to its widespread.

2 Announcers in-game would praise the player's performance, announcing loud expressions like "Pentakill" or "[Player Name] is on a killing spree!". Ranks with several categories were also created that could even be shared online and serve to validate players' accomplishments and their performances. 
created their own language, where either by voice or by typing, terms like, "n00bs" and "pwned" have become typical for referring to personal achievements or player performances.

By the early millennium, online services provided a means for gaming experiences that seemed tailored to male audiences. Quick reflexes, action gameplay mechanics, bonus for praising performances, and leaderboards and ranks weren't exactly new, but online services allowed them to reach mass audiences. No longer was the gaming community dependent on in-person gaming tournaments in physical venues to feed their desire for competition. In the internet age, players in the comfort of their own home could still compete with neighbours, but also people in other territories or countries. Computer games mods like Counter-Strike (2000), or custom maps like Defense of the Ancient (DotA) became famous in the computer gaming world. Soon organizations grew around this movement, leading to more eSports communities and organized teams. Gaming studios, acknowledging the value of these high-exposure markets, created gameplay experiences tailored to their needs, or organized huge events with significant monetary sums offered as prizes. Dota 2 (Valve, 2012), League of Legends (Riot Games, 2009), and Counter Strike, are among the famous games for which developers continually create conditions for competitiveness to thrive in their audiences. For these communities, games that were using unrealistic graphics, or without any competitive redeeming quality weren't for "real gamers". According to Zagal and Johnson (2009, p. 220) games that usually use the full technical potential of the platform tend also to be considered better. According to Kubick (2010, p.72), this discourse and sometimes inflammatory accusations from the avowed hardcore gamers can sometimes lead to other players being accused of not rightfully belonging to the gaming community. Emotional connection has become so important that games seem tailored to create fractious situations, ensuring a stream of contentious content.
In 2013, during the GDC conference "The Applied Value of Player Psychology: Putting Motivational Principles to Work", Troy Skinner (Warner Bros Games) and Scott Rigby (Immersyve), acknowledged that there were two principal console audiences - Brogamers and connoisseur gamers. In their definition, Bro Gamers comprised $65 \%$ of the market, playing only a few games (usually the most popular titles), preferring quick action games. Their main goal was entertainment. On the other hand, connoisseurs, who are 15\% of the market share, tend to brand themselves as gamers by adopting merchandise or similar, evangelize their chosen game towards others, and prefer to play what they consider innovation and depth titles. In the view of both Skinner and Rigby, one of the main challenges is creating games that appeal to both of these audiences.

\section{The developer-superfan feedback loop}

The definition of who is a fanboy is quite diverse, and it's not unique to the gaming audience. In fact, they can be found in other creative media productions - movies, comic books are among the most populous communities. For companies, they represent the perfect public, and in some cases, they thrive in creating mechanisms or conditions for the audience to become superfans of their product. Authors like Fournier (2015, pp. 343-352), define Superfans as obsessive, committed, and able to create an intimate relationship with their objects of worship. Due to the interactive and engaging nature of video games, this kind of audience can really become even more susceptible and reach different levels of obsession. Strong emotions run high in this community. Authors like James, Fletcher (2016, pp. 122-123), consider that the gamers that become superfans - or fanboys as they are more commonly known among gamer and developer cultures - can become even aggressive, both in their gaming sessions and outside of them. 
The relationship between game developers and their super-fan is one that is extensively cultivated by the marketing departments of major game companies. The perfect consumer is the one that never sees faults in the product, and even evangelizes it, or actively defends it. But, for production teams, this relation can be perilous. Adding extra content into a game can be interpreted as a clever business decision however pleasing audiences in this way can jeopardize the project's creative vision.

(...) these fans actively affect the industry; they force, unknowingly or not, developers into making decisions to please them. This results in a variety of problems and is prevalent in larger companies as well. (James, Fletcher, 2016)

This feedback loop between development and production can quickly become an issue, where "the narrow tastes of the majority become a major economic driving force behind big-budget game development" (Baxter-Webb, 2014, pp. 5-6). An example is the Sonic the Hedgehog (SEGA, 1991) Intellectual Property, which originated in the 16-bit era of consoles. Marketing departments heavily promoted the games using buzzwords mostly referring to game speed and quick gameplay. Sonic games become a synonym of swiftness and dexterity, engendering these as audience expectations. And so developers had to accommodate them. In the next console generation cycle, the transition for 3D became a trend. Mario core gameplay made a fluid evolution, and the same was expected from Sonic titles. The results of previous years, and marketing buzzwords meant that "speed" was to be considered an essential game design concern, since the audience demanded it. Three Sonic titles were developed, but only Sonic $R$ (Traveller's Tales, Sonic TEAM, 1997) was in pure 3D³ , and speed was at the forefront. Upon release the game received mixed critical reviews. Speed became a Sonic game designer's main challenge with the audience expectations holding the game developers hostage. This would later even start an unpopular trend called Sonic Cycle - high audience expectations for a title following the title's announcement, constant hype growing during game development, culminating in a disappointing game release (but with average stable sales that ensure the process will repeat).

In the case of the Sonic Intellectual Property, for years the fanboy communities expectations were detrimental to game development. Fanboys and their respective communities can act as both a blessing and a curse in product success. They are indeed a part of the gaming community fabric, assuming in some cases, a symbiotic relationship between industry and audiences.

However, it should be acknowledged that in more recent years the industry has diversified into more demographics, territories, and online stores. This made content available where gaming historically had difficulty penetrating. And although the male audience arguably still factors disproportionately, the available products and titles are more diverse than ever.

\section{The industry workforce}

Between 2000 and 2010, getting a published title in console was arduous. Game engine licences were quite expensive, and console SDK as well. In fact, it was such a challenge that some companies would even spend the first years developing their own game engine instead of licensing another middleware. Besides that, the major retail market was based on distribution of boxed copies on physical storage media, with store logistics accounting for a significant share of the

3 Sonic Jam and Sonic 3D Blast were the two others. The first one is a compilation of previous generation titles, while the second, although it boasts the "3D" term in the name, it's not made of polygons, but a clever use of sprites. So, it's not a quite pure 3D title. Both of them are not original games, since they had versions on the previous console cycle. 
production budget. During this period, developers struggled to get a foothold in the market:

Marketing obviously influences sales figures, but the prevailing retail system of pre-ordering means that games without a sufficient pre-launch buzz may not get much shelf space; and by the time the word of mouth gets around, it can be too late. (Berens, Howard, 2008, p.215).

Labor organization was (and is) a significant hurdle in the industry. Poor labour conditions, crunch-time, and massive layoffs are just a few issues that have always troubled the game development workforce. In answer to these conditions, several organizations have appeared in recent years, such as Syndicat des Travailleuse'eurs's du Jeu Vidéo in France, or Game Makers of Finland. But still a lot of territories don't have any sort of such organization, and workplace abuses persist, even where such organizations have a presence.

In 2019, Activision CEO Bobby Kotick wrote in a press release to investors stating:

while our financial results for 2018 were the best in our history, we didn't realize our full potential. To help us reach our full potential, we have made a number of important leadership changes. These changes should enable us to achieve the many opportunities our industry affords us, especially with our powerful owned franchises, our strong commercial capabilities, our direct digital connections to hundreds of millions of players, and our extraordinarily talented employees.

At almost the same time, Activision started massive layoffs and cuted 775 jobs, which was about 8 percent of their workforce (Buckley, 2019). At the time Activision was responsible for major games franchises, such as Overwatch, Call of Duty and Diablo.
These issues tend to be overlooked by the public, since like mentioned before, working in game development is considered a privilege. Even as far as 2000, David Kushner, while observing Ion Storm development of Daikatana, reported in the online magazine Salon:

Since Daikatana inception, elite and obsessive gamers have road-tripped from around the world to work with their hero, [John] Romero. They've quit school, left relationships and literally built beds under their desks to live and breathe nearly every breath in the house Romero built. Their commitment to a self-described "deathschedule" - the final, endless rush to perfect their game - isn't just some start-up novelty, it's a way of life. (Kushner, 2000)

The described "death-schedule" is a synonym for "Crunch-time", but the above story also points out how gamers-turned-developers accepted poor working conditions just to have the title ready on time. In the case of Daikatana, the game's release became infamous, and Ion Storm would eventually close their doors. But, it isn't an unique case. In 2018, Dan Houser, RockStart Games co-founder, casually admitted in an interview that his workforce was working 100work weeks while in the final development stage of Red Dead Redemption 2 (Goldberg, 2019).

As it can be observed, encouraging game development workforce as exceptional and privileged can lead game workers to be perceived as people who will endure workplace abuses and aren't entitled to the same rights as workers in other industries. Even something as elementary as being named in the product's credits can become a problem. Games resist the concept of single authorship. The film industry resolved this through the role of the director and of actors, but there is no equivalent for games. Only a few figures in the gaming industry are acknowledged as game authors, and even fewer are known outside of it. Gaming audiences are also more 
likely to know the product, than its author, even if it was developed by a smaller 1-4 members team.

\section{Conclusion}

Regarding digital games, it is not uncommon for people interested in becoming creative professionals in the games industry to have been exposed to the medium, usually at a young age. In this, digital games are similar to other media.

Game developers tend to identify at first as gamers. In gamer communities, the idea of doing labour in their favorite leisure activity can be considered more than a job, something closer to privilege and unfortunately, managing these expectations can become an issue. With growing development budgets and tightening schedules in the digital games industry, industry workers continue to be exposed to the same detrimental working conditions. Audiences might want, or at least expect games with ongoing technical breakthroughs. However, having to deliver these breakthroughs in a shortened development cycle can be a grueling, thankless process. There is still a long way to go in overcoming these issues in professional cultures in the games industry.

Organizations have emerged for dealing with these issues, and since more information about development is available, game development is losing the magical and exotic status which contributed to toxic workplaces and labour violations. Games industry labor organization can help in restoring that balance, uniting not only for workers, but also with companies. These expectations between audiences and development are therefore quite delicate, and a condition for progress in these issues.

\section{References}

Ryan, B. (1991). Making Capital from Culture: the Corporate Form of CapitalistCultural Production. Berlin: De Gruyter.
Barroso, I. (2018). Revolução Interactiva: Compêndio Visual Computadores, jogos eletrônicos, consolas domésticas e portáteis, Amsterdam: Blurb edition.

Baxter-Webb, J. (2014). Divergent Masculinities in Contemporary Videogame Culture: A Tale of Geeks and Bros. In Joyce, L. and Quinn, B. (org.). Mapping the Digital: Cultures and Territories of Play. Oxford: Interdisciplinary Press.

Berems, K. \& Geoff, H. (2008). The Rough Guide to Videogames, London: Rough Guides.

Buckley, S. (2019), "Activision Blizzard begins employee layoffs after best year in company history", Cnet, 12 February, 2019. www.cnet.com/news/activision-blizzard-begins-employee-layoffs-after-best-year-in-company-history/ (online: Accessed 14 $4^{\text {th }}$ April 2020).

Christiansen, P. (2013). Breaking Out of the Industry: The Independent Games Movement as Resistance to Hegemonic Videogame Discourse. USA: The University of Utah.

Consalvo, M. (2017) Cheating: Gaining Advantage in Videogames. London: MIT Press.

David, N. (2011). Triple-A: The political economy of the blockbuster video game, Amsterdam: University of Amsterdam.

David, N. (2012). Fewer and Bigger: The rise of the über-blockbuster video game, Amsterdam: University of Amsterdam.

Dymek, M. (2012). Videogames: A Subcultural Industry In The Video Game Industry: Formation, Present State, and Future. London: Routledge.

Ensslin, A (2012). The Language of Gaming. London Palgrave macmillan, 2012 
Evans, D., Hagiu, Andrei, S., Schmalensee, R. (2008). Invisible Engines: How Software Platforms Drive Innovation and Transform Industries, Local: The MIT press.

Goldberg, H. (2018) "How the West Was Digitized The making of Rockstar Games' Red Dead Redemption 2", 14 October 2019, Vulture. www.vulture.com/2018/10/the-making-ofrockstar-games-red-dead-redemption-2.html, (online: accessed $24^{\text {th }}$ April 2020).

Izushi, H., Aoyama, Y. (2010). Industry Evolution and Cross-Sectoral Skill Transfers: A Comparative Analysis of the Video Game Industry in Japan, the United States, and the United Kingdom.

Juul, J. (2010). A Casual Revolution: Reinventing Video Games and Their Players. Cambridge: The MIT Press.

Kubik, E. (2012). Masters of Technology: Defining and Theorizing the Hardcore/Casual Dichotomy in Video Game Culture. In Cyberfeminism, edited by Radhika Gaijala and Yeon Ju Oh, 135-152. New York: Peter Lang Publishing.

Kushner, D. (2003). Masters of Doom: How two guys created an empire and transformed pop culture, London, Piatkus.

Martin, C., Deuze, M. (2009). The Independent production of culture: A digital games case study.

O'Donnell, C. (2008) The work/play of the interactive new economy. Videogame development in the United States and Indie, Rensselaer Polytechnic Institute.

Rufat, S. et. al (2012) "Situating play cultures. A survey of videogame players and practices in France". Ludespace. Hovden, Jan, Klevjer, Rune (2012), "Game space and social space". Norsk Medieforskerkonferanse.
Semules, A. (2019), 'Every Game You Like Is Built on the Backs of Workers.' Video Game Creators Are Burned Out and Desperate for Change" Time, https://time.com/5603329/e3-video-game-creators-union/ (online: accessed at 5th May 2020)

Sliwinski, A. (2007), "Wii is two duct taped Gamecubes and other publisher rants" Engadget, www.engadget.com/200703-08-wii-is-two-duct-taped-gamecubes-and-otherpublisher-rants.html? (online accessed at 5th May 2020)

Sheff, D. (1993). Game Over: Nintendo battle to dominate an industry. London, Coronet Book.

Schatz, T. (2003) "The New Hollywood," in Movie blockbusters, J. Stringer. London: Routledge.

Zagal, J. Ladd, A., Johnson, T. (2009) Characterizing and understanding game reviews, Proceedings of the 4th International Conference on Foundations of Digital Games - FDG '09. April. 215-222 